\title{
Efficacy of resveratrol to supplement oral nifedipine treatment in pregnancy-induced preeclampsia
}

\section{Endocrine CONNECTIONS}

\author{
Jian Ding ${ }^{1,2}$, Yan Kang ${ }^{1,2}$, Yuqin Fan ${ }^{1,2}$ and Qi Chen ${ }^{3}$ \\ ${ }^{1}$ Department of Obstetrics and Gynecology, Maternal and Child Health Care Hospital of Shandong Province, Jinan, \\ Shandong Province, China \\ 2Department of Obstetrics and Gynecology, Provincial Hospital Affiliated to Shandong University, Jinan, \\ Shandong Province, China \\ ${ }^{3}$ Department of Obstetrics and Gynecology, Zoucheng People's Hospital, Zoucheng, Shandong Province, China
}

Correspondence

should be addressed

to Q Chen

Email

jnzccq@126.com

\begin{abstract}
Objective: Preeclampsia (PE) is a complication affecting pregnant women worldwide, which usually manifests as severe maternal hypertension. Resveratrol (RESV), a naturally existing polyphenol, is known to exhibit beneficial effects in cardiovascular disease including hypertension. We evaluated the outcome of treatment combining oral nifedipine (NIFE) and RESV against PE.

Design and methods: Using a randomized group assignment, 400 PE patients were enrolled and received oral treatments of either NIFE + RESV or NIFE + placebo. Primary endpoints were defined as time to control blood pressure and time before a new hypertensive crisis. Secondary endpoints were defined as the number of doses needed to control blood pressure, maternal and neonatal adverse effects.

Results: Compared with the NIFE + placebo group, the time needed to control blood pressure was significantly reduced in NIFE + RESV group, while time before a new hypertensive crisis was greatly delayed in NIFE + RESV group. The number of treatment doses needed to control blood pressure was also categorically lower in NIFE + RESV group. No differences in maternal or neonatal adverse effects were observed between the two treatment groups.

Conclusion: Our data support the potential of RESV as a safe and effective adjuvant of oral NIFE to attenuate hypertensive symptoms among PE patients.
\end{abstract}

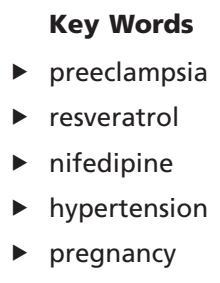

Endocrine Connections (2017) 6, 595-600

\section{Introduction}

Preeclampsia (PE) is a severe disease that manifests in multiple systems, and uniquely occurs during pregnancy, usually after 20 weeks of gestation (1). PE remains the leading cause of mortality and morbidity during pregnancy for women worldwide, and its most detrimental symptoms are severe elevated blood pressure and proteinuria. Thus, to monitor and control blood pressure of PE patients are important in the clinical management of $\operatorname{PE~}(2,3)$, in which anti-hypertensive drugs are commonly found to be of clinical efficacy in relieving hypertension (4).
(C) 2017 The authors Published by Bioscientifica Ltd
Nifedipine (NIFE) is among several first-line antihypertensive treatments among PE patients $(3,5,6)$. NIFE is a $\mathrm{Ca}^{2+}$ channel inhibitor (5) and functions to reduce vascular resistance by improving renal blood flow, as well as elevate urine output by repressing release of anti-diuretic hormones. Therefore, NIFE has become a potent antihypertensive agent for effective blood pressure control during pregnancy (7). Importantly, NIFE has been proven to be clinically safe, especially for pregnant patients (8). When prescribed in the 3rd trimester, administration of http://www.endocrineconnections.org DOI: 10.1530/EC-17-0130

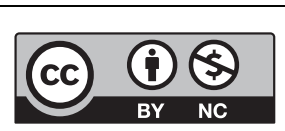

This work is licensed under a Creative Commons Attribution-NonCommercial 4.0 International License. 
NIFE was able to effectively control high blood pressure, whereas it did not cause any serious adverse effects on either maternal or fetal development (9). In addition, NIFE has also been employed for treating pre-term labor without showing any perinatal adverse effects (10). Of particular relevance to our current study, in severe PE patients, NIFE was reported to improve arterial pressure and urine output in immediate puerperium (11).

Resveratrol (3,4,5-trihydroxy-trans-stilbene, RESV), a natural polyphenol extracted from fruits such as grapes and cranberries, has exhibited beneficial effects in various cardiovascular diseases (12). For instance, in rat model of PE, RESV was reported to reduce blood pressure (13), as well as inhibit trophoblast apoptosis through oxidative stress (14). In a pregnant mouse model with reduced blood supply to the uterus, RESV increased uterine artery blood flow velocity and fetal weight (15). In spontaneously hypertensive rats, RESV could lower blood pressure through production of calcium-dependent endothelial NO (16). In addition, in a recent clinical trial among patients with primary hypertension, RESV was able to supplement standard anti-hypertensive therapy to effectively reduce blood pressure to normal levels (17). Altogether these above studies support the promising potential of RESV as a potent anti-hypertensive agent.

In the current clinical trial, we aimed to use RESV as an adjuvant of oral NIFE treatment against pregnancyinduced severe PE and examine the treatment efficacy as well as potential adverse effects.

\section{Materials and methods}

\section{Ethics}

This is an intent-to-treat study. Design of the current clinical trial followed the guidelines of Declaration of Helsinki, and this study protocol was approved by the Ethical Committee in the Maternal and Child Health Care Hospital of Shandong Province. All patients enrolled in the study have signed written informed consent forms.

\section{Patient selection}

From June 2013 to November 2016, a total of 400 women carrying singleton pregnancy, aged between 21 and 32 years, were diagnosed of severe PE in hospital and subsequently agreed to participate in the current study.
All patients required blood pressure control treatments, among which 51 patients were excluded due to exclusion criteria: (1) history of treatment with anti-hypertensive drugs; (2) history of heart failure during the course of the pregnancy.

\section{Randomization process and drug treatment}

349 patients were eventually eligible for the randomization process, who were randomly assigned, using a permutedblock design stratified according to their diastolic blood pressure, into two treatment groups: (1) NIFE + RESV group $(n=174)$, administered oral NIFE capsule (Quancheng Pharmaceuticals, Shandong, China; $10 \mathrm{mg}$ each, up to 5 dosages) and RESV capsule (Yixin Pharmaceuticals, Zhejiang, China; $50 \mathrm{mg}$ each, up to 5 dosages) every $15 \mathrm{~min}$ until blood pressure $\leq 150 / 100 \mathrm{mmHg}$; (2) NIFE+ placebo group ( $n=175)$, administered oral NIFE capsule (10 mg each, up to 5 dosages) plus glucose capsule $(50 \mathrm{mg}$ each, up to 5 dosages) as placebo every $15 \mathrm{~min}$ until blood pressure $\leq 150 / 100 \mathrm{mmHg}$. Once blood pressure of the patient reached $\leq 150 / 100 \mathrm{mmHg}$, no further dose was administered. Investigators blind to the group assignment prepared the RESV and placebo capsules identical in appearance to mask the content to patients.

\section{Definition of endpoints}

Primary endpoints were defined as: (1) time needed to bring blood pressure to no higher than 150/100 $\mathrm{mmHg}$; (2) time before a new hypertensive crisis. Secondary endpoints were defined as: (1) the number of doses needed to bring blood pressure to no higher than 150/100 mmHg; (2) maternal and neonatal adverse effects. All measurements were performed by investigators blind to the group assignment.

\section{Anthropometrics}

Body weight was measured with patients in light clothing and no shoes standing straight on a digital scale with $0.1 \mathrm{~kg}$ accuracy. Body height was measured with patients standing straight without shoes standing straight on a stadiometer with $0.1 \mathrm{~cm}$ accuracy. Body mass index (BMI) was defined as body weight/(body height) ${ }^{2}$ in $\mathrm{kg} / \mathrm{m}^{2}$. Blood pressure was measured by a digital blood pressure monitor with $0.1 \mathrm{mmHg}$ accuracy. http://www.endocrineconnections.org
DOI: 10.1530/EC-17-0130 (c) 2017 The authors Published by Bioscientifica Ltd
This work is licensed under a Creative Commons Attribution-NonCommercial 4.0 International License. 


\section{Adverse effects}

At the end of the trial, all patients were asked to complete a questionnaire on the symptoms of nausea, vomiting, maternal tachycardia, mild headache, dizziness, chest pain, hypotension and shortness of breath they might had in the process of the study. During the treatment, the maternal and fetal heart rates were under constant monitoring.

\section{Statistical analysis}

Student $t$ test and Pearson chi-square test were performed appropriately to address differences in data between the two treatment groups. The 95\% confidence intervals (CI) were calculated, and $P<0.05$ indicated statistically significant difference. All statistical analyses were performed using SPSS 18.0 (SPSS).

\section{Results}

As shown in Fig. 1, from June 2013 to November 2016, 400 pregnant PE patients, carrying singleton pregnancy aged between 21 and 32 years and, were initially enrolled for the study. Fifty-one participants were subsequently excluded, and the remaining eligible 349 participants were randomly assigned to two treatment groups. 174 patients were instructed to administer oral NIFE+RESV, and 175 patients were instructed to administer oral NIFE+ placebo, with one dose every $15 \mathrm{~min}$ until their blood pressure was controlled to $\leq 150 / 100 \mathrm{mmHg}$. Table 1 compared the anthropometrics, including maternal age, gestational age, systolic and diastolic blood pressures, heart rate, body weight, body height and BMI, of all 349 participants between the two treatment groups. We did not observe any significant differences between patients from the two treatment groups.

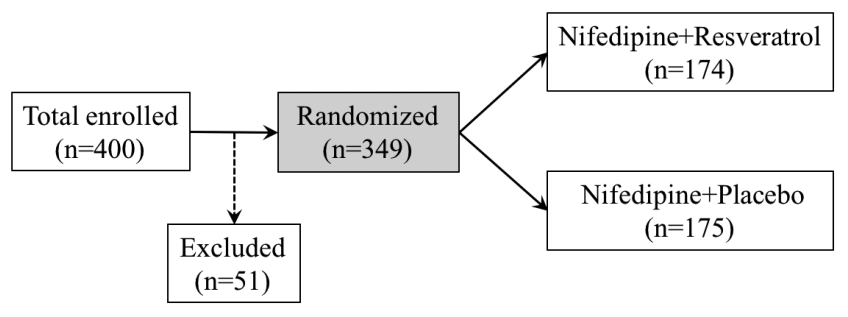

Figure 1

Illustration of study design.

$$
\begin{aligned}
& \text { http://www.endocrineconnections.org } \\
& \text { DOI: 10.1530/EC-17-0130 }
\end{aligned}
$$

Table 1 Characteristics of patients from the two treatment

\begin{tabular}{|c|c|c|c|}
\hline Characteristics & $\begin{array}{c}\text { NIFE + RESV } \\
(n=174)\end{array}$ & $\begin{array}{l}\text { NIFE + placebo } \\
\quad(n=175)\end{array}$ & $P$ value \\
\hline Maternal age (year) & $27.1 \pm 6.2$ & $26.9 \pm 7.1$ & 0.41 \\
\hline Gestation age (week) & $34.7 \pm 3.4$ & $33.4 \pm 4.1$ & 0.52 \\
\hline $\begin{array}{l}\text { Systolic blood pressure } \\
(\mathrm{mmHg})\end{array}$ & $169.1 \pm 15.2$ & $171.4 \pm 16.1$ & 0.28 \\
\hline $\begin{array}{l}\text { Diastolic blood pressure } \\
(\mathrm{mmHg})\end{array}$ & $107.9 \pm 9.6$ & $112.4 \pm 10.1$ & 0.13 \\
\hline Heart rate (/min) & $84.1 \pm 10.2$ & $86.4 \pm 9.4$ & 0.27 \\
\hline Body weight (kg) & $64.8 \pm 3.6$ & $63.1 \pm 4.8$ & 0.31 \\
\hline Body height (m) & $1.67 \pm 0.12$ & $1.65 \pm 0.11$ & 0.20 \\
\hline BMI $\left(\mathrm{kg} / \mathrm{m}^{2}\right)$ & $23.5 \pm 3.1$ & $24.4 \pm 3.8$ & 0.37 \\
\hline
\end{tabular}
groups.

BMI, body mass index; NIFE, nifedipine; RESV, resveratrol.

Table 2 summarized primary endpoints of the two treatment groups. First, the time required to effectively control blood pressure in the NIFE+RESV group was $35.6 \pm 18.7 \mathrm{~min}$. While in the NIFE+placebo group it was $51.1 \pm 22.4 \mathrm{~min}$, significantly longer than the NIFE+RESV group ( $P=0.01$; 95\% CI 4.7-10.9). Next, the time before a new hypertensive crisis following effective blood pressure control in the NIFE+RESV group was $8.0 \pm 2.1 \mathrm{~h}$. While it was $5.5 \pm 1.8 \mathrm{~h}$ in the NIFE+placebo group, significantly shorter than the NIFE+RESV group $(P=0.02 ; 95 \%$ CI $0.3-2.4)$.

We next evaluated secondary endpoints of both the treatment groups. As shown in Fig. 2, the number of doses needed to control blood pressure was significantly lower in the NIFE+RESV group than the NIFE+placebo group. At last, at the end of trial, maternal and neonatal adverse effects were summarized in Table 3. Between the two treatment groups, we did not observe any significant differences for maternal adverse effects, in terms of nausea, vomiting, maternal tachycardia, mild headache, dizziness, chest pain, hypotension or shortness of breath. In addition, we did not find any differences in neonatal adverse effects between the two treatment groups, in terms of birth weight and Apgar scores of the newborns.

\section{Discussion}

Anti-hypertensive therapies are critical for controlling severe hypertension during pregnancy-induced PE (18) and also important for lowering incidence rate of both maternal and fetal complications (19, 20). Currently, clinical choices of proper use of drugs for hypertension management among PE patients are often made empirically, among which NIFE is one of first-line drugs commonly prescribed for controlling severe high blood

This work is licensed under a Creative Commons Attribution-NonCommercial 4.0 International License. 
Table 2 Efficacy of the two treatments in controlling blood pressure among preeclampsia patients.

\section{Primary endpoints}

Time to control blood pressure (min)

Time before a new hypertensive crisis (h)

\begin{tabular}{c} 
NIFE + RESV $(n=174)$ \\
\hline $35.6 \pm 18.7$ \\
$8.0 \pm 2.1$
\end{tabular}

\begin{tabular}{c} 
NIFE + placebo $(n=175)$ \\
\hline $51.1 \pm 22.4$ \\
$5.5 \pm 1.8$
\end{tabular}

NIFE, nifedipine; RESV, resveratrol.

pressure during pregnancy $(3,6)$. Compared with other anti-hypertensive alternatives, oral NIFE is cheaper, safer and more effective in achieving similar anti-hypertensive efficacy against pregnancy-induced PE $(5,21)$.

Due to extra diligence and considerations for pregnancy, PE patients often find themselves with a lack of available anti-hypertensive drugs, despite the fact that these drugs are widely used for hypertension patients without pregnancy. Therefore, a novel and safe drug with clinical efficacy to complement oral NIFE could greatly benefit PE patients. In line with the above notion, RESV is a natural extract from fruits such as grapes, and also enriched in drinks such as red wine. Due to its natural and safe origin, the use of RESV has been reported

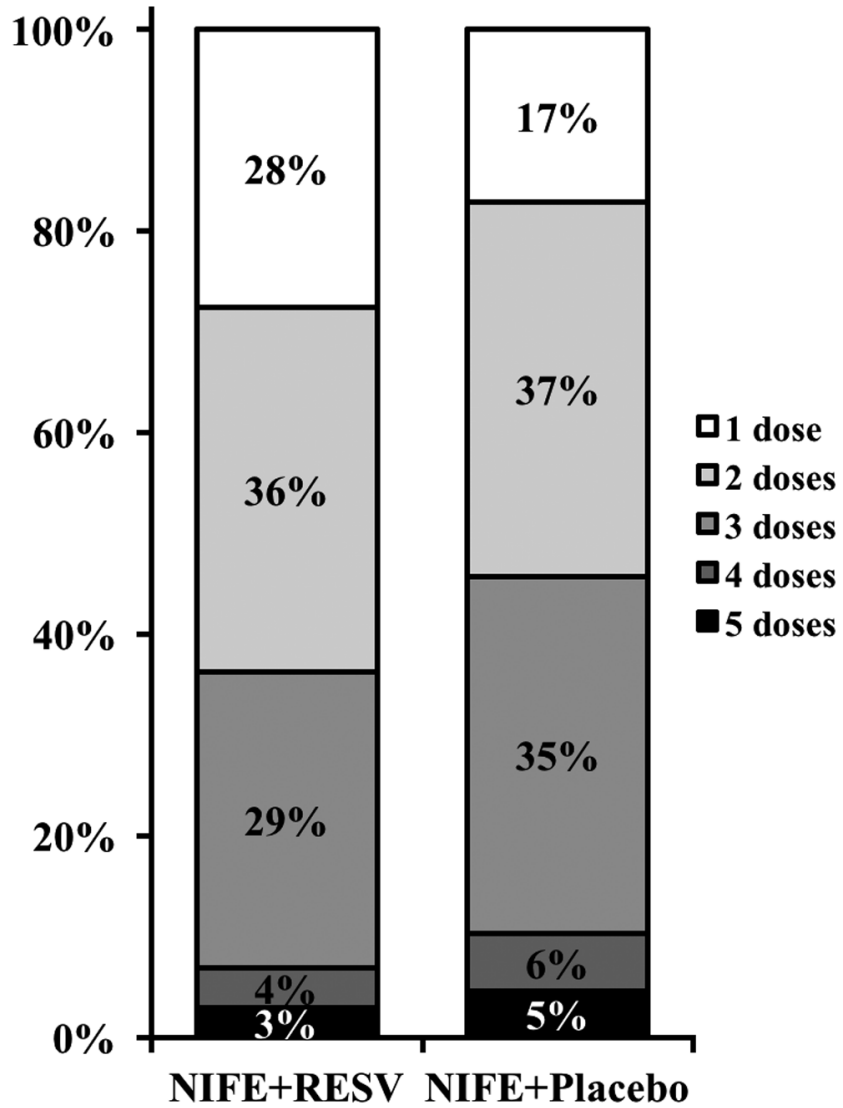

Figure 2

Number of doses needed to control blood pressure in two groups of patients. Percentages do not add up to 100 due to rounding.

$$
\text { http://www.endocrineconnections.org }
$$$$
\text { DOI: 10.1530/EC-17-0130 }
$$

in complications during pregnancy (22), including gestational diabetes mellitus (23). Of particular interest to our current study, the anti-hypertension property of RESV has also been demonstrated in a number of studies employing both animal and clinical studies (13, 14, 15, 16, 17). Given its widely reported anti-hypertensive function, we therefore also employed RESV in the current clinical trial among pregnant women affected by PE, with the hypothesis that RESV could also exhibit benefits in relieving hypertension in pregnancy-induced PE.

Results from our clinical trial have demonstrated that, the combinational treatment of oral NIFE+ RESV has significantly improved both the primary and secondary endpoints, compared with NIFE+placebo treatment. Compared with the NIFE + placebo group, the time needed to control blood pressure was significantly reduced in NIFE+RESV group, while time before a new hypertensive crisis was greatly delayed in NIFE+RESV group. The number of treatment doses needed to control blood pressure was also categorically lower in NIFE+RESV group. Most importantly concerning the pregnant PE patients, we did not find any severe adverse effects, maternal or neonatal, associated with RESV administration, suggesting the clinical safety of RESV among pregnant women.

Despite the observed clinical efficacy of RESV in complementing oral NIFE, the underlying mechanism of

Table 3 Adverse effects and neonatal complications of the two treatments.

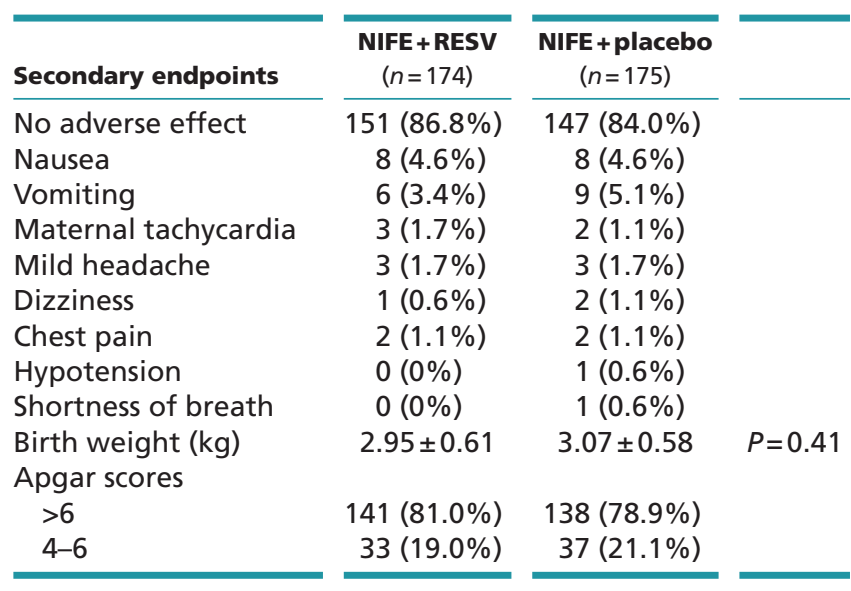

NIFE, nifedipine; RESV, resveratrol.

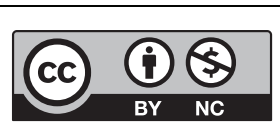

This work is licensed under a Creative Commons Attribution-NonCommercial 4.0 International License. 
RESV action in relieving hypertension is still unknown. It has been reported that RESV could inhibit the release of soluble fms-like tyrosine kinase (sFlt-1) from human placenta (22). It is possible that sFlt- 1 may be the molecular target underlying the anti-hypertensive property of RESV, since sFlt-1 itself is a reliable biomarker for clinical prediction of PE $(24,25,26,27,28,29)$. Besides sFlt-1, matrix metalloproteinase (MMP)-2 and MMP-9 were also reported to be involved in the pathology of $\mathrm{PE}$, both as predictive biomarkers and as drug targets $(30,31,32,33)$. Given the great body of studies reporting the function of RESV in regulating levels and activities of both MMP-2 and MMP-9 $(34,35,36,37)$, these two MMPs are also likely to be the mediating factor of RESV in relieving hypertension of PE patients. Further studies are currently underway to evaluate the above potential mechanisms, particularly a larger scale multicenter trial is needed.

To conclude, our current randomized, placebocontrolled and double-blinded clinical trial is the first to report the potency, as well as safety, of RESV as a promising adjuvant to complement oral NIFE therapy, which could greatly enhance the clinical efficacy of treatments against hypertension of severe pregnancy-induced PE.

\section{Declaration of interest}

The authors declare that there is no conflict of interest that could be perceived as prejudicing the impartiality of the research reported.

\section{Funding}

This work did not receive any specific grant from any funding agency in the public, commercial, or not-for-profit sector.

\section{References}

1 Bijvank SW, Visser W, Duvekot JJ, Steegers EA, Edens MA Roofthooft DW, Vulto AG \& Hanff LM. Ketanserin versus dihydralazine for the treatment of severe hypertension in early-onset preeclampsia: a double blind randomized controlled trial. European Journal of Obstetrics and Gynecology and Reproductive Biology 2015189 106-111. (doi:10.1016/j.ejogrb.2015.02.002)

2 Abalos E, Duley L \& Steyn DW. Antihypertensive drug therapy for mild to moderate hypertension during pregnancy. Cochrane Database of Systematic Reviews 20142 CD002252. (doi:10.1002/14651858. CD002252.pub3)

3 Magee LA, Helewa M, Moutquin JM \& von Dadelszen P, Hypertension Guideline C \& Strategic Training Initiative in Research in the Reproductive Health Sciences S. Diagnosis, evaluation, and management of the hypertensive disorders of pregnancy. Journal of Obstetrics and Gynaecology Canada 200830 S1-S48. (doi:10.1016/ S1701-2163(16)32776-1)

4 Belfort MA, Anthony J, Buccimazza A \& Davey DA. Hemodynamic changes associated with intravenous infusion of the calcium antagonist verapamil in the treatment of severe gestational proteinuric hypertension. Obstetrics and Gynecology 199075 970-974.
5 Fenakel K, Fenakel G, Appelman Z, Lurie S, Katz Z \& Shoham Z. Nifedipine in the treatment of severe preeclampsia. Obstetrics and Gynecology 199177 331-337.

6 Duley L, Meher S \& Jones L. Drugs for treatment of very high blood pressure during pregnancy. Cochrane Database of Systematic Reviews 20137 CD001449. (doi:10.1002/14651858.CD001449.pub3)

7 Giannubilo SR, Bezzeccheri V, Cecchi S, Landi B, Battistoni GI, Vitali P, Cecchi L \& Tranquilli AL. Nifedipine versus labetalol in the treatment of hypertensive disorders of pregnancy. Archives of Gynecology and Obstetrics 2012286 637-642. (doi:10.1007/s00404012-2371-x)

8 Clark SM, Dunn HE \& Hankins GD. A review of oral labetalol and nifedipine in mild to moderate hypertension in pregnancy. Seminars in Perinatology 201539 548-555. (doi:10.1053/j.semperi.2015.08.011)

9 Childress CH \& Katz VL. Nifedipine and its indications in obstetrics and gynecology. Obstetrics and Gynecology 199483 616-624. (doi:10.1097/00006250-199404000-00024)

10 Ferlinz J. Nifedipine in myocardial ischemia, systemic hypertension, and other cardiovascular disorders. Annals of Internal Medicine 1986 105 714-729. (doi:10.7326/0003-4819-105-5-714)

11 Barton JR, Hiett AK \& Conover WB. The use of nifedipine during the postpartum period in patients with severe preeclampsia. American Journal of Obstetrics and Gynecology 1990162 788-792. (doi:10.1016/0002-9378(90)91011-Z)

12 Bonnefont-Rousselot D. Resveratrol and cardiovascular diseases. Nutrients 20168 250. (doi:10.3390/nu8050250)

13 Moraloglu O, Engin-Ustun Y, Tonguc E, Var T, Tapisiz OL, Ergun H, Guvenc T \& Gacar A. The effect of resveratrol on blood pressure in a rat model of preeclampsia. Journal of Maternal-Fetal and Neonatal Medicine 201225 845-848. (doi:10.3109/14767058.2011.599081)

14 Zou Y, Zuo Q, Huang S, Yu X, Jiang Z, Zou S, Fan M \& Sun L. Resveratrol inhibits trophoblast apoptosis through oxidative stress in preeclampsia-model rats. Molecules 201419 20570-20579. (doi:10.3390/molecules191220570)

15 Poudel R, Stanley JL, Rueda-Clausen CF, Andersson IJ, Sibley CP, Davidge ST \& Baker PN. Effects of resveratrol in pregnancy using murine models with reduced blood supply to the uterus. PLOS ONE 20138 e64401. (doi:10.1371/journal.pone.0064401)

16 Li X, Dai Y, Yan S, Shi Y, Li J, Liu J, Cha L \& Mu J. Resveratrol lowers blood pressure in spontaneously hypertensive rats via calciumdependent endothelial NO production. Clinical and Experimental Hypertension 201638 287-293. (doi:10.3109/10641963.2015.1089882)

17 Theodotou M, Fokianos K, Mouzouridou A, Konstantinou C, Aristotelous A, Prodromou D \& Chrysikou A. The effect of resveratrol on hypertension: a clinical trial. Experimental and Therapeutic Medicine 201713 295-301. (doi:10.3892/etm.2016.3958)

18 Shi Q, Leng W, Yao Q, Mi C \& Xing A. Oral nifedipine versus intravenous labetalol for the treatment of severe hypertension in pregnancy. International Journal of Cardiology 2015178 162-164. (doi:10.1016/j.ijcard.2014.10.111)

19 Brown MA, Hague WM, Higgins J, Lowe S, McCowan L, Oats J, Peek MJ, Rowan JA, Walters BN \& Austalasian Society of the Study of Hypertension in Pregnancy. The detection, investigation and management of hypertension in pregnancy: full consensus statement. Australian and New Zealand Journal of Obstetrics and Gynaecology 2000 40 139-155. (doi:10.1111/j.1479-828X.2000.tb01137.x)

20 Rey E, LeLorier J, Burgess E, Lange IR \& Leduc L. Report of the Canadian Hypertension Society Consensus Conference: 3. Pharmacologic treatment of hypertensive disorders in pregnancy. CMAJ 1997157 1245-1254

21 Aali BS \& Nejad SS. Nifedipine or hydralazine as a first-line agent to control hypertension in severe preeclampsia. Acta Obstetricia et Gynecologica Scandinavica 200281 25-30. (doi:10.1034/j.16000412.2002.810105.x)

22 Cudmore MJ, Ramma W, Cai M, Fujisawa T, Ahmad S, Al-Ani B \& Ahmed A. Resveratrol inhibits the release of soluble fms-like tyrosine http://www.endocrineconnections.org DOI: 10.1530/EC-17-0130
(๑) 2017 The authors Published by Bioscientifica Ltd
This work is licensed under a Creative Commons Attribution-NonCommercial 4.0 International License. 
kinase (sFlt-1) from human placenta. American Journal of Obstetrics and Gynecology 2012206 253.e210-253.e255. (doi:10.1016/ j.ajog.2011.11.010)

23 Tran HT, Liong S, Lim R, Barker G \& Lappas M. Resveratrol ameliorates the chemical and microbial induction of inflammation and insulin resistance in human placenta, adipose tissue and skeletal muscle. PLOS ONE 201712 e0173373. (doi:10.1371/journal. pone.0173373)

24 Dragan I, Wright D, Fiolna M, Leipold G \& Nicolaides KH. Development of pre-eclampsia within 4 weeks of sFlt-1/PlGF ratio >38: comparison of performance at 31-34 vs 35-37 weeks' gestation. Ultrasound in Obstetrics and Gynecology 201649 209-212. (doi:10.1002/uog.17310)

25 Frusca T, Gervasi MT, Paolini D, Dionisi M, Ferre F \& Cetin I. Budget impact analysis of sFlt-1/PIGF ratio as prediction test in Italian women with suspected preeclampsia. Journal of Maternal-Fetal and Neonatal Medicine 201630 2166-2173. (doi:10.1080/14767058.2016.1 242122)

26 Klein E, Schlembach D, Ramoni A, Langer E, Bahlmann F, Grill S, Schaffenrath H, van der Does R, Messinger D, VerhagenKamerbeek WD, et al. Influence of the sFlt-1/PIGF ratio on clinical decision-making in women with suspected preeclampsia. PLoS ONE 201611 e0156013. (doi:10.1371/journal.pone.0156013)

27 Perales A, Delgado JL, De La Calle M, Garcia-Hernandez JA, Escudero AI, Campillos JM, Sarabia MD, Laiz B, Duque M, Navarro M, et al. sFlt-1/PIGF for early-onset pre-eclampsia prediction: STEPS (Study of Early Pre-eclampsia in Spain). Ultrasound in Obstetrics and Gynecology 201650 373-382. (doi:10.1002/uog.17373)

28 Vatish M, Strunz-McKendry T, Hund M, Allegranza D, Wolf C \& Smare C. sFlt-1/PlGF ratio test for pre-eclampsia: an economic assessment for the UK. Ultrasound in Obstetrics and Gynecology 201648 765-771. (doi:10.1002/uog.15997)

29 Zeisler H, Llurba E, Chantraine F, Vatish M, Staff AC, Sennstrom M, Olovsson M, Brennecke SP, Stepan H, Allegranza D, et al. Predictive value of the sFlt-1:PlGF ratio in women with suspected preeclampsia. New England Journal of Medicine 2016374 13-22. (doi:10.1056/ NEJMoa1414838

30 Lavee M, Goldman S, Daniel-Spiegel E \& Shalev E. Matrix metalloproteinase-2 is elevated in midtrimester amniotic fluid prior to the development of preeclampsia. Reproductive Biology and Endocrinology 20097 85. (doi:10.1186/1477-7827-7-85)

31 Montagnana M, Lippi G, Albiero A, Scevarolli S, Salvagno GL, Franchi M \& Guidi GC. Evaluation of metalloproteinases 2 and 9 and their inhibitors in physiologic and pre-eclamptic pregnancy. Journal of Clinical Laboratory Analysis 200923 88-92. (doi:10.1002/jcla.20295)

32 Plaks V, Rinkenberger J, Dai J, Flannery M, Sund M, Kanasaki K, Ni W, Kalluri R \& Werb Z. Matrix metalloproteinase-9 deficiency phenocopies features of preeclampsia and intrauterine growth restriction. PNAS 2013110 11109-11114. (doi:10.1073/ pnas.1309561110)

33 Palei AC, Granger JP \& Tanus-Santos JE. Matrix metalloproteinases as drug targets in preeclampsia. Current Drug Targets 201314 325-334.

34 Gweon EJ \& Kim SJ. Resveratrol attenuates matrix metalloproteinase-9 and -2-regulated differentiation of HTB94 chondrosarcoma cells through the p38 kinase and JNK pathways. Oncology Reports 201432 71-78. (doi:10.3892/or.2014.3192)

35 Pandey AK, Bhattacharya P, Shukla SC, Paul S \& Patnaik R. Resveratrol inhibits matrix metalloproteinases to attenuate neuronal damage in cerebral ischemia: a molecular docking study exploring possible neuroprotection. Neural Regeneration Research 201510 568-575. (doi:10.4103/1673-5374.155429)

36 Chen Z, Hu L, Lu M \& Shen Z. Resveratrol reduces matrix metalloproteinases and alleviates intrahepatic cholestasis of pregnancy in rats. Canadian Journal of Physiology and Pharmacology 201694 402-407. (doi:10.1139/cjpp-2015-0454)

37 Chen J, Bai Q, Zhao Z, Sui H \& Xie X. Resveratrol improves delayed r-tPA treatment outcome by reducing MMPs. Acta Neurologica Scandinavica 2016134 54-60. (doi:10.1111/ane.12511)

Received in final form 24 August 2017

Accepted 12 September 2017 http://www.endocrineconnections.org DOI: 10.1530/EC-17-0130 (c) 2017 The authors Published by Bioscientifica Ltd

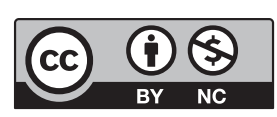

This work is licensed under a Creative Commons Attribution-NonCommercial 4.0 International License. 